\title{
Macro and Micro Anatomical Observation on the Testes of Local Dog (Canis lupusfamiliaris) of Assam
}

\author{
A. Deka, D. Kalita, K.B. Devchoudhury, J. Kachari, R.J. Deka, M.J. Bhuyan
}

10.18805/IJAR.B-4797

\begin{abstract}
Background: The study on testes of local dog of Assam is of great value in regard to germplasm conservation. The aim of the study was to evaluate the gross and histomorphological examination of testes of male reproductive system.

Methods: The testes were collected at the time of castration from Department of Surgery and Radiology, College of Veterinary Science, Assam Agricultural University, Khanapra, Guwahati, Assam, India. The research was carried out for a period of one year in Department of Anatomy and Histology, College of Veterinary Science, Assam Agricultural University, Khanapara, Guwahati, Assam. Then gross anatomical studies were made on it and the tissue samples were fixed in $10 \%$ neutral buffered formalin solution and were processed as per the standard technique of procedure (Luna, 1968). The paraffin blocks were sectioned in Shandon Finesse microtome at $5 \mu \mathrm{m}$ thickness and the sections were stained with Mayer's Haematoxylin and Eosin staining technique for Cellular details as per the method of Luna (1968).

Result: Grossly, the testes of local dog consisted of two surface viz., lateral and medial and two ends i.e. upper end and lower end. The upper end of the testes was occupied by the head of the epididymis and the lower end of the testes was occupied by the tail of the epididymis. Mediastinum testis was observed in the centre of testes of local dog. Histologically, the testes were covered by serous layer (Tunica vaginalis), connective tissue layer (Tunica albugenia) and vascular layer (Tunica vasculosa) from outside to inwards. Spermatogenic cells like spermatogonia, primary spermatocytes, secondary spermatocytes, spermatids and spermatozoa, and sertoli cells were observed in seminiferous tubules. The sertoli cells were attached to the basement membrane of seminiferous tubules. Cluster of Leyding cells were found between the semineniferous tubules and it contained large spherical nuclei. The epididymides were lined by pseudo stratified ciliated columnar epithelium.
\end{abstract}

Key words: Anatomy, Local dog, Macro, Micro, Testis.

\section{INTRODUCTION}

The dog was the first species to be domesticated, by human being, before the development of agriculture. They perform great roles for human being, such as hunting, pulling of loads, protection, assisting police and the military, companionship, therapy and aiding physically handicapped persons. They are considered as man's best friends. A testis is a vital organ of male reproductive system. It produces spermatozoa and testosterone hormone. The macro and micro anatomy of testis is the essential base for understanding normal physiology, histopathology, endocrinology, surgical anatomy and to evaluate the breeding efficiency in local dog of Assam. In male dogs, breeding efficiency depends on the production of androgens by the interstitial cells of testis, which also influence the process of spermatogenesis. (Bhagyalakshmi et al., 2020) reported that the architecture of testes is disorganizes in various diseases related to the testis of male dogs, such as testicular tumors (TT) which are the most common neoplasms. Apart from the testicular tumors the seminomas and Leydig cell tumor also disorganized the testes. Meagre reports are existing on the micro and macro anatomy of testis in local dog of Assam when compared with other domestic animals; hence the present study was designed to establish an anatomical norm on this organ of the male reproductive system.
Department of Anatomy and Histology, College of Veterinary Science, Assam Agricultural University, Khanapara, Guwahati-781 022, Assam, India.

Corresponding Author: A. Deka, Department of Anatomy and Histology, College of Veterinary Science, Assam Agricultural University, Khanapara, Guwahati-781 022, Assam, India.

Email: dranilvet01@gmail.com

How to cite this article: Deka, A., Kalita, D., Devchoudhury, K.B., Kachari, J., Deka, R.J., Bhuyan, M.J. (2021). Macro and Micro Anatomical Observation on the Testes of Local Dog (Canis lupusfamiliaris) of Assam. Indian Journal of Animal Research. DOI: $10.18805 /$ IJAR.B-4797.

Submitted: 04-10-2021 Accepted: 11-12-2021 Online: 01-01-2021

\section{MATERIALS AND METHODS}

The study was conducted on the six numberstestes of the local dog (Canis lupusfamiliaris). The testes were collected at the time of castration from Department of Surgery and Radiology, College of Veterinary Science, Assam Agricultural University, Khanapara, Guwahati, Assam, India. Then gross anatomical studies were made on it and the tissue samples were fixed in $10 \%$ neutral buffered formalin solution and were processed as per the standard technique of procedure (Luna, 1968). The paraffin blocks were sectioned in Shandon Finesse microtome at $5 \mu \mathrm{m}$ thickness 
and the sections were stained with Mayer's Haematoxylin and Eosin staining technique for cellular details as per the method of Luna (1968). The research was carried out in Department of Anatomy and Histology, College of Veterinary Science, Assam Agricultural University, Khanapara, Guwahati, Assam for a period of six months

\section{RESULTS AND DISCUSSION}

Gross studies on testes and epididymis of local dog of Assam

The testes of local dog of Assam were reddish white in colour with oval in shape. The testes had of two surface viz., lateral and medial and two ends i.e. upper end and lower end. The lateral surface of testes was convex and the medial surface of testes was flat. The upper end of the testes was occupied by the head of the testes whereas the lower end of the testes was attached to the tail of the epididymis. Mediastinum testis was found in the centre of testes of local dog of Assam. The mediastinum testes were white in colour and well developed in local dog of Assam (Fig 2). The epididymis was consisted of head, body and tail and attached to the testes (Fig 1).

The testes of local dog of Assam were reddish white colour with oval in shape. Similar finding was reported by Bhagyalakshmi et al., (2020) in dog. The testes had of two surface viz., lateral and medial and two ends i.e. upper end and lower end. The lateral surface of testes was convex and the medial surface of testes was flat. The upper end of the testes was occupied by the head of the testes whereas the lower end of the testes was attached to the tail of the epididymis. Mediastinum testis was found in the centre of testes of local dog of Assam. The mediastinum testes were white in colour and well developed in local dog of Assam. These finding was in accordance with the findings of Sisson and Grossman (1953). The epididymis was consisted of head, body and tail and attached to the testes. These finding were total agreement with the findings of Ghosh (2015) in cattle.

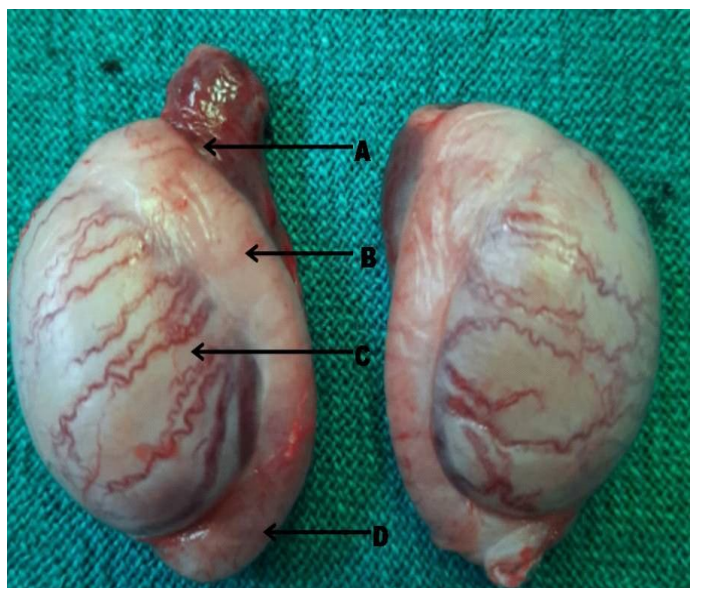

Fig1: Photograph showing the head of epididymis (A), body of the epididymis (B), testes (C) and tail of the epididymis (D) of local dog of Assam.
Histo-morphological studies on testes of local dog of Assam

Histologically, the testes local dog of Assam were covered by tunica vaginalis, tunica albugenia and tunica vasculosa from outside to inwards (Fig 3). The tunica albugenia was a solid capsule of dense irregular connective tissue. The tunica albuginea was covered by the serous layer i.e. the tunica vaginalis. Tunica vasculosa layer was present in the deeper part of the tunica albuginea. Numbers of cross section of blood vessels were observed in the tunica vasculosalayer. The parenchymatous part of the testes was divided into numbers lobules by thick trabeculae or septae which were derived from the tunica albuginea. Numbers of cross-section of blood vessels was found in the septae. The lobules of the testes contained seminiferous tubules, interstitial connective tissue, interstitial cells and blood vessels (Fig 4). Each seminiferous tubule was surrounded by a basement membrane along with smooth muscles. These tubules contained sertoli cells and spermatogenic cells. The spermatogenic cells were spermatogonia, primary

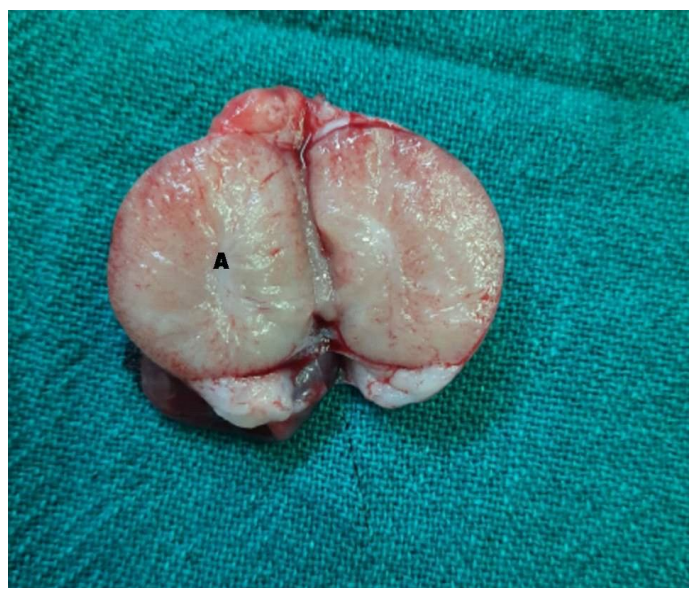

Fig 2: Photograph showing the mediastinum testes of local dog of Assam.

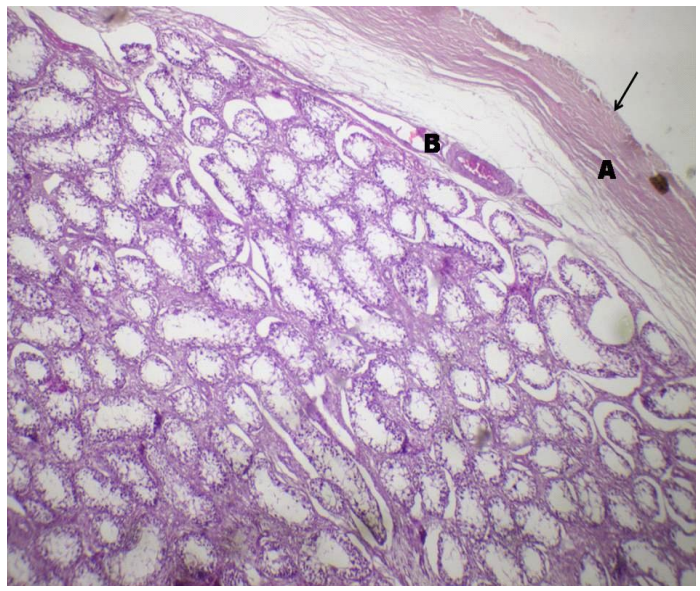

Fig 3: Photomicrograph showing the tunica vaginalis (arrow), tunica albugenia (A) and tunica vasculosa (B) of testes of local dog of Assam. H\&E, X10. 


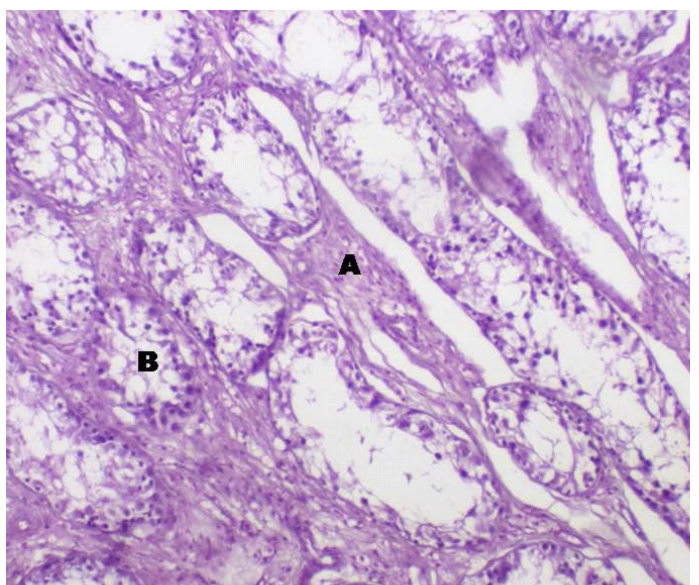

Fig 4: Photomicrograph showing the interstitial connective tissue (A) and cross section of seminiferous tubules (B) of testes of local dog of Assam. H\&E, X10.

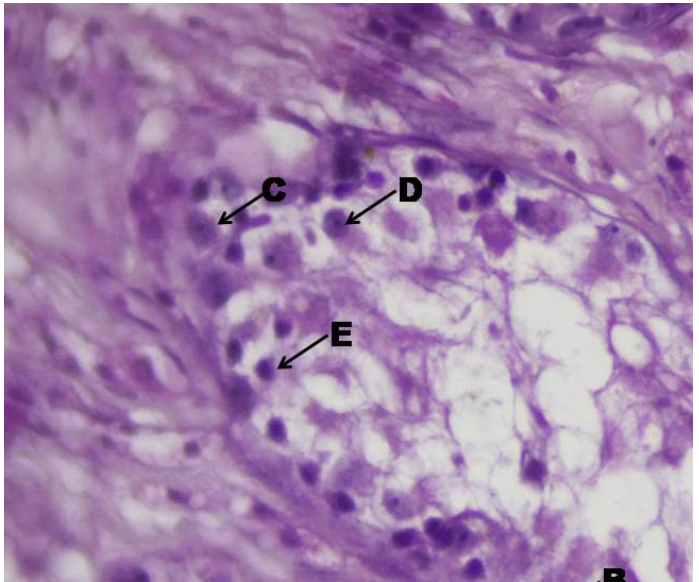

Fig 5: Photomicrograph showing the basement membrane of seminiferous tubules $(A)$, sertoli cell $(B)$, spermatogonia (C), primary spermatocytes $(D)$, secondary spermatocytes $(E)$, Leyding cells $(F)$ and cross section of blood vessels $(G)$ of testes of local dog of Assam. H\&E, X40.

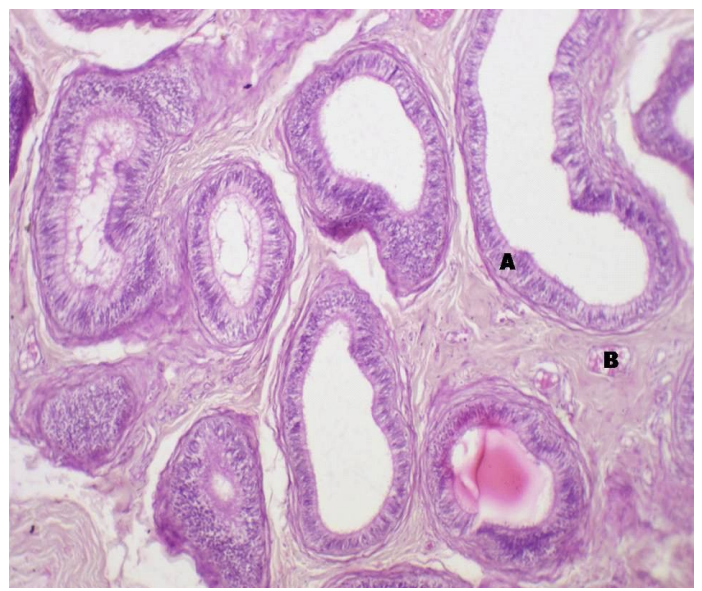

Fig 6: Photomicrograph showing the pseudo stratified ciliated columnar epithelium (A) and cross section of blood vessels (B) of epididymis of local dog of Assam. H\&E, X10. spermatocytes, secondary spermatocytes, spermatids and spermatozoa (Fig 5). Similar observations were reported by Mahmud et al., (2015) in testes of one-humped camel bull and Kishore et al., (2012) in testes of ram. The sertoli cells were attached to the basement membrane of seminiferous tubules. The spermatogonia were very prominent near the basement membrane whereas the spermatids and spermatocytes were present towards the lumen of the seminiferous tubules. The mature spermatids and few spermatozoa occluded the lumen of seminiferous tubules. Interstitial connective tissue and cluster of Leyding cells were found between the semineniferous tubules. The shape of nuclei of leyding cells were large spherical. Apart from the leyding cells, cross-section of blood vessels was foundin interstitial connective tissue. The lining epithelium of epididymis was pseudostratified ciliated columnar epithelium along with basal and columnar cells (Fig 6). The lumens of the epididymis were wide. The cilia of epididymis were stereocilia which help in the movement of spermatozoa (Fig 7). Spermatozoa were also observed in the lumen of epididymis. The epididymides were surrounded by layers of loosely arranged smooth muscles and basement membrane.

Histologically, the testes local dog of Assam was covered by tunica vaginalis, tunica albugenia and tunica vasculosa from outside to inwards. The tunica albugenia was a solid capsule of dense irregular connective tissue. The tunica albuginea was covered by the serous layer i.e. the tunica vaginalis. Tunica vasculosa layer was present in the deeper part of the tunica albuginea. Numbers of cross section of blood vessels were observed in the tunica vasculosa layer. The parenchymatous part of the testes was divided into numbers lobules by thick trabeculae or septae which were derived from the tunica albuginea. Numbers of cross-section of blood vessels was found in the septae. These findings were in accordance with the findings of Moonji and Suwanpugdee (2007) in the testis of Rusa deer. The lobules of the testes seminiferous tubules, interstitial

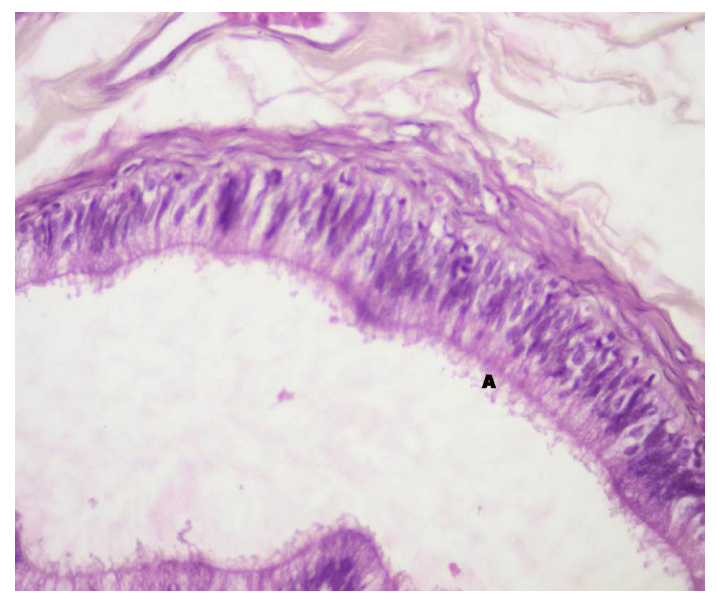

Fig 7: Photomicrograph showing the stereocilia $(A)$ of pseudo stratified ciliated columnar epithelium of epididymis of local dog of Assam. H\&E, X40. 
tissue, interstitial cells and blood vessels. Each Seminiferous tubule was surrounded by a basement membrane along with smooth muscles. These tubules contained sertoli cells and spermatogenic cells. The spermatogenic cells were spermatogonia, primary spermatocytes, secondary spermatocytes, spermatids and spermatozoa. These findings were also supported by Gofur et al. (2008) in the indigenous bull of Bangladesh. The sertoli cells were attached to the basement membrane of seminiferous tubules. Similar findings were reported by Mohammed et al. (2011) in the testes of an indigenous male goat. The spermatogonia were very prominent near the basement membrane whereas the spermatids and spermatocytes were present towards the lumen of the seminiferous tubules. The mature spermatids and few spermatozoa occluded the lumen of seminiferous tubules. Interstitial connective tissue and cluster of Leyding cells were found between the semineniferous tubules. The shape of nuclei of Leyding cells were large spherical. Apart from the Leyding cells, crosssection of blood vessels was found in interstitial connective tissue. These findings were in accordance with the findings of Deka et al. (2014) in testes of Pygmy hog and Elzoghby et al. (2014) in testes of Sheep. The lining epithelium of epididymis was pseudostratified ciliated columnar epithelium along with basal and columnar cells. The lumens of the epididymis were wide. The cilia of epididymis were stereocilia which help in the movement of spermatozoa. Spermatozoa were also observed in the lumen of epididymis. The epididymides were surrounded by layers of loosely arranged smooth muscles and basement membrane.Similar observations were reported by Semkov et al. (1984) in testes of calves.

\section{CONCLUSION}

Thorough knowledge of the macro and micro anatomy of testis is very essential in elucidating its role in physiology, histopathology, endocrinology, surgical anatomy. The testes of local dog of Assam were ovoid in shape. The testes had of two surface viz., lateral and medial and two ends i.e. upper end and lower end. The epididymis was consisted of head, body and tail and it attached to the testes. The testes local dog of Assam was covered by tunica vaginalis, tunica albugenia and tunica vasculosa from outside to inwards. Seminiferous tubules contained sertoli cells and spermatogenic cells. Cluster of Leydig cells were found in interstitial connective tissue. The lining epithelium of epididymis was pseudo stratified ciliated columnar epithelium. This study will help in evaluate the breeding efficiency in local dog of Assam.

\section{ACKNOWLEDGEMENT}

The authors are grateful to the Dean, College of Veterinary Science, Assam Agricultural University, Khanapara, Assam, India for providing the required facilities to conduct this experiment.

\section{REFERENCES}

Bhagyalakshmi, J., Balasundaram, K., Selvaraj, P., Kathirvel, S., Balachandram, P. and Chandana, G.S.S. (2020). Gross, histology and histochemical analysis of the testes in dog (Canis lupus familiaris). Journal of Entomology and Zoology. 8(4): 69-73.

Deka, A., Sarma, K. and Das, B.J. (2014). Histomorphological observation on the testes of Pygmy Hog (Porcula salvania). Indian Veterinary Journal. 91(5): 82-83.

Elzoghby, E.M.A., Sosa, G.A. and Mona, N.A.H. (2014). Postnatal development of the sheep testes. Benha Veterinary Medicine of Journal. 26: 186-190.

Ghosh, R.K. (2015). Primary Veterinary Anatomy, (6 $6^{\text {th }}$ Edn). Current Books International 60, Lenin Sarani, Kolkata. Pp 268-271.

Gofur, M.R., Khan, M.Z.I., Karim, M.R. and Islam, M.N. (2008). Histomorphology and histochemistry of testes of indigenous bull (Bosindicus) of Bangladesh. Bangladesh Journal of Veterinary Medicine. 6(1): 67-74.

Kishore, P.V.S., Ramesh G. and Sabiha, H.B. (2012). Postnatal differentiation of spermatogenic cells in the testes of ram. Tamilnadu Journal of Veterinary and Animal Sciences. 8(6): $340-344$.

Luna, L.G. (1968). Manuals of Histological Staining Methods of Armed Forces Institute of Pathology, ( $3^{\text {rd }}$ Edn.). McGraw Hill Book Co., New York.

Mahmud, M.A., Onu, J.E., Shehu, S.A., Umaru, M.A., Danmaigoro, A. and Bello, A. (2015). Comparative gross and histological studies on testes of one-humped camel bull, uda ram and red sokoton buck. International Journal of Multidisciplinary Research and Information. 1: 81-84.

Mohammed, A.H.S., Kadium, D.A.H. and Ebed, A.K. (2011). Some morphometric and histological descriptions of the seminiferous, striaghted and rete testes tubules in the of indigenous male goats (two years old). Kufa Journal of Veterinary Medical Science. 2(1): 19-29.

Moonji, P. and Suwanpugdee, A. (2007). Histological structure of testis and ductus epididymis of Rusa Deer (Cervus timorrensis). Kasetsart Journal (Nature of Science). 41: 86-90.

Semkov, M., Kovachev, K. and Zhuroval, D. (1984). Histological characteristics of the testis and epididymis of calves during postnatal development. Veterinary Medicine Nauki. 21(1): 76-80.

Sisson, S. and Grossman, J.D. (1953). The Anatomy of the Domestic Animals. $4^{\text {th }}$ Edn. W.B. Saunders Company, Phildelphia and London. 